\title{
Entrevista a Graciela Iglesias
}

Lucía Briguet: ¿Podes contarnos cómo funciona el órgano de revisión y cuál es la situación en las diferentes provincias? ¿Hay un único modo de funcionamiento o en las diferentes provincias tiene diferentes formas?

Graciela Iglesias: El Órgano de Revisión fue creado por la Ley Nacional de Salud Mental y tiene su fundamento en los estándares de derechos humanos y en los 21 principios de Naciones Unidas para la protección del enfermo mental Res. 46/119 Asamblea General de Naciones Unidas diciembre de 1991. El marco de actuación que tiene el Órgano de Revisión es el siguiente: es un organismo de monitoreo, de supervisión del sistema de salud mental, velando por los derechos de las personas que se encuentran bajo ese sistema en cualquiera de las intervenciones que pudiesen existir o que la persona pudiera realizar o estar comprometido su derecho. En ese sentido tiene una doble función, por un lado, el organismo nacional cumple una especie de rectoría en el resto del país marcando los estándares de seguimiento que están entrecruzados con los derechos humanos y a partir de los derechos humanos es que se supervisa un sistema sanitario, entonces hay una relación que tiene que ver con los casos particulares y con los casos que están en un proceso de internación. Todavía Argentina regula la internación involuntaria entonces esa regulación implica un control de legalidad por el debido proceso y entonces ahí tenemos un control estricto sobre las internaciones. Y, por otro lado, tiene un trabajo más político institucional que es de promoción, supervisión, recomendaciones, requerimientos, dictámenes que atraviesa a todos los colectivos que están implicados desde una perspectiva de derechos humanos y por supuesto de género, así como lo que es el paradigma de la infancia. Con personas mayores igual, aunque habría que detenerse un poco en establecer la diferenciación en cuanto a las personas mayores y el tratamiento que las personas mayores reciben desde la ley de salud mental.

La situación de los Órganos provinciales ha sido una meta del Órgano Nacional, es decir, la promoción de los órganos de revisión locales. El país está cubierto de Órganos de Revisión o de leyes que tienen a su implementación, por ejemplo: toda la Patagonia tiene Órgano de Revisión, La Pampa tiene un proyecto de ley que ha quedado detenido en el ejecutivo, en Mendoza tiene media sanción y eventualmente puede perder estado parlamentario este año si no se sanciona, San Luis tiene su ley de desinstitucionalización y hay que continuar con el trabajo para la creación del Órgano de Revisión, la Rioja está en este momento reglamentando su ley de Salud Mental y Órgano de Revisión o sea que se suma al Órgano de Revisión, Catamarca de la misma manera, La Rioja finaliza el proceso para la implementación efectiva y Catamarca la comienza, Jujuy tiene su Órgano de Revisión pero no ha dado cumplimiento a la secretaria ejecutiva, la provincia de Tucumán está con la reglamentación de la ley, Chaco está en pleno funcionamiento, Misiones tiene la ley de Salud Mental pero no han legislado sobre el Órgano de Revisión es una cuestión que está pendiente a realizarse, Corrientes tiene un proyecto de ley para la implementación del Órgano de Revisión, Entre Ríos está en pleno funcionamiento, Santa Fe comienza ahora en pleno funcionamiento del Órgano de Revisión se está concursando el cargo de secretaria ejecutiva, Córdoba está en un proceso de definición para la sanción de la ampliación de la ley que constituya el Órgano de Revisión local, Buenos Aires tiene su Órgano 
de Revisión asentado en la defensoría del pueblo y Santiago del Estero tiene un proyecto de ley y el compromiso para la creación del Órgano de Revisión. Así que el país está cubierto en las distintas etapas de los Órganos de Revisión. Todos funcionan con los mismos ejes que el nacional, exactamente todos, de hecho, tenemos un consejo federal donde intercambiamos y encuentros con cada una de las provincias para acompañar el proceso y para definir líneas de actuación. Pero todos los Órganos de Revisión tienen un mismo lineamiento a nivel nacional y cuidamos mucho que eso se sostenga y se mantenga.

L.B.: ¿Qué ventajas y desventajas encuentra en los diferentes lugares?

G.I.: Las ventajas y desventajas que existen tienen que ver con la idiosincrasia de la cultura y de las prácticas que existen en cada una de las regiones, eso es favorable en un sentido y puede ser una barrera en otro sentido. Pero no hay circunstancias desfavorables que uno pueda visualizar en relación al funcionamiento, puede haber mayor esfuerzo, mayor trabajo, mayor necesidad de incidir sobre las barreras existentes, pero no existen desventajas, por lo menos no en lo que se visualiza hasta este momento.

L. B.: ¿Cuáles son las cuestiones que el Órgano de Revisión va agendando como problemáticas a resolver o los obstáculos que encuentra para poder efectivizar la aplicación de la ley?

G.I.: La agenda que tiene el Órgano de Revisión como objetivo general es el atravesamiento del ejercicio y disfrute de la capacidad jurídica de las personas, o sea, la toma de decisiones y con eso viene la vida independiente, poder vivir de manera autónoma con los apoyos que se requieran. Eso implica que nuestra preocupación está en el proceso de desinstitucionalización y en este año que es el 2020 en la transformación del sistema, en la sustitución de un sistema por otro y esto es altamente complejo. Pero la efectiva implementación es una definición que creo que en este año es una definición de gobierno y entonces todo lo que se haga se va a hacer en torno a generar este nuevo sistema que contenga un sistema de atención a la salud que sea respetuoso del derecho de las personas a vivir en comunidad y a través de un modelo de vida independiente con los apoyos que se requieran dónde salud es un aspecto más pero no es el único.

Los obstáculos son múltiples pero el mayor obstáculo son las estructuras armadas desde tanto tiempo atrás, la conciencia, la cultura, la falta de dispositivos o presupuestos, pero quizás lo primero sea desarmar y destruir los mandatos estructurales que tienen que ver con la monovalencia en el sentido de que únicamente un hospital psiquiátrico es el único que está capacitado para atender la salud mental. Eso debe desplazarse a un concepto más integral de lo que es la salud mental y después las lógicas, las capacitaciones, la formación de quienes intervienen que complejiza porque a veces se quedan desentrañando en lo que le pasa a quienes intervienen y no puede haber un desplazamiento total hacia poner el centro en la persona exclusivamente. Esas son las barreras más grandes pero además las personas usuarias del sistema todavía, salvó en alguna región, no pueden organizarse debidamente porque hay muchos atravesamientos que se lo impiden que tienen que ver con esa lógica que mencionaba sumado a una pobreza estructural que en lo que es la institucionalización psiquiátrica aún persiste y en lo que es el modelo de atención requiere de una amplitud para generar una red integrada de cuidados y que esos cuidados sean cuidados continuos con los apoyos que las personas necesitan pero también con la libertad y la dignidad que merecen. 